\title{
El goce como estrategia de construcción del cuerpo post sida
}

\section{Raúl García Sangrador ${ }^{1}$}

\section{Resumen}

Recepción: 15 de mayo de 2017 / Aprobación: 11 de setiembre de 2017

El presente artículo estudia la experiencia y la producción estética resultante de la enfermedad, partiendo de las definiciones de placer y goce de Roland Barthes; el neobarroco de Severo Sarduy; el erotismo de Georges Bataille, y el festejo o carnaval, de Mijail Bajtin. Para ello, se realiza un análisis de la erótica de la enfermedad desde dos estudios de caso (Robert Gober y Raúl García Sangrador), donde el arte recurre al fenómeno del sida para crear nuevos significados de la corporalidad actual. Se concluye que, a partir del goce, es posible definir la erótica de la enfermedad como un reto para el entendimiento del arte actual y un espacio de tensión en donde el sida se convierte en un fenómeno artístico-político.

\section{Palabras clave}

Arte contemporáneo; corporalidad; estética; erotismo; enfermedades

\section{Abstract}

The present article studies the experience and the aesthetic production resulting from the disease, starting from the definitions of pleasure and enjoyment of Roland Barthes; the neo-baroque of Severo Sarduy; the eroticism of Georges Bataille, and the celebration or carnival, by Mijail Bajtin. For this, an analysis of the erotica of the disease is carried out from two case studies (Robert Gober and Raúl García Sangrador), where art uses the AIDS phenomenon to create new meanings of the current corporality. It is concluded that, from enjoyment, it is possible to define the erotic of the disease as a challenge for the understanding of current art and a space of tension where AIDS becomes an artistic-political phenomenon.

\section{Keywords}

Contemporary art; corporality; esthetic; eroticism; diseases

$1 \quad$ Mexicano. Doctor en Artes por la Universidad de Guanajuato, México. Docente Investigador de Tiempo Completo en la Facultad de Bellas Artes, de la Universidad Autónoma de Querétaro, México. Correo electrónico: filisangrador@gmail.com 


\section{Resumo}

O presente artigo estuda a experiência e a produção estética resultante da doença, a partir das definições de prazer e gozo de Roland Barthes, do neo-barroco de Severo Sarduy, do erotismo de Georges Bataille e da celebração ou do carnaval de Mikhail Bajtin. Para isso, realiza-se uma análise do erotismo da doença, a partir de dois estudos de caso (Robert Gober e Raúl García Sangrador), onde a arte usa o fenômeno da AIDS para criar novos significados da corporeidade atual. Conclui-se que, a partir do gozo, é possível definir o erótico da doença como um desafio para a compreensão da arte atual e um espaço de tensão no qual a AIDS se torna um fenômeno artístico-político.

\section{Palavras chave}

Arte contemporânea; corporalidade; estética; erotismo; doenças

\section{Post sida}

El 3 de julio de 1981 se publicó en el New York Times una nota sobre un cáncer raro detectado en 41 homosexuales, principalmente en las ciudades estadounidenses de New York y San Francisco (Altman, 1981, p. A 20). Esa fue la primera vez que la prensa escrita abordó el tema, con cierta reticencia, en parte por las políticas conservadoras de la administración de Ronald Reagan (1981-1989). Desde entonces a la fecha, han ocurrido una serie de sucesos que obligan a hacer un alto y observar cómo el sida ha generado matices dentro de las estructuras sociales de todos los países alrededor del mundo. El arte también ha registrado estas consecuencias, creando poéticas particulares, en las que los conceptos de salud, enfermedad, cuerpo y muerte han sido problematizados y puestos en conflicto desde la mirada médica, antropológica, histórica, estética, entre otros. El presente ensayo propone el neologismo pos sida para referir a este período de 36 años, desde la nota del cáncer raro del New York Times.

\section{El goce como estrategia de la enfermedad}

En la Galería Juana de Aizpuru de Madrid ví por primera vez, en el año 2003, una exposición fotográfica de Joel Peter Witkin² (n. 1939). La mayoría de sus tomas son puestas en escena; estas parten del conflicto con lo corporal, del cadáver y los cuerpos atípicos que se convierten en temas de reflexión. Una de las fotografías de dicha exposición se ligó profundamente en mi pensamiento: Corpus Medius, fechada en el año 2000. Se trata de una foto blanco y negro de unas piernas masculinas bien torneadas sobre una mesa con mantel oscuro. Es la mitad de alguien que en vida seguro hacía ejercicio; un cadáver cortado por la cintura con las vísceras expuestas. El 
pene se ve flácido y de prepucio largo que, junto con los testículos, cae de lado por la gravedad. Desde ese día de 2003 a la fecha no puedo dejar de pensar que esa fotografía es profundamente erótica; definitivamente puedo afirmar que contemplar una imagen como Corpus Medius genera en mí una experiencia estética ${ }^{3}$, pero ¿es posible que un cuerpo cercenado a la mitad pueda despertar erotismo en el espectador? ¿Es posible hablar de placer estético? Witkin presenta sus imágenes como piezas de arte abyecto, el cual se fundamenta principalmente en el pensamiento de Georges Bataille, en dos textos esenciales: Las Lágrimas de Eros (2002) y "El Erotismo" (Breve historia del Erotismo, 1970).

Bataille descubre que, en ciertos momentos, la mente humana genera una amalgama en la que lo más despreciable toma el mismo estatus que lo más sagrado; el erotismo es quien aglutina con tánatos. Así, el cadáver es el elemento abyecto por excelencia. Hal Foster habla de esto en El retorno de lo real y marca una disyuntiva con André Bretón, cercano al psicoanálisis freudiano y que se contrapone a la propuesta batailliana (Foster, 2001, p. 163). Esto me representó un conflicto: ¿estoy equivocado al afirmar que la fotografía cadavérica de Witkin me produce una experiencia estética? ¿Solo a mí me ocurre? Mi amigo Fabián Giménez Gatto me comentó que tal vez es más acertado decir que se trata de goce, más que de placer estético. ¿Cómo se crea esta diferencia? Roland Barthes hace una propuesta a partir de definir dos instancias:

-) Texto de placer: el que contenta, colma, da euforia; proviene de la cultura, no rompe con ella y está ligado a una práctica confortable de la lectura.

-) Texto de goce: el que pone en estado de pérdida, desacomoda (tal vez incluso hasta una forma de aburrimiento), hace vacilar los fundamentos históricos, culturales, psicológicos del lector, la congruencia de sus gustos, de sus valores y de sus recuerdos, pone en crisis su relación con el lenguaje. (Barthes, 2011, p. 22).

En otras palabras, Barthes marca dos rutas de cómo abordar un texto, ya sea de placer o goce. El primero implica lo inmediato, fácil y confortable; el segundo implica una confrontación con lo establecido, es la búsqueda del entendimiento. ¿Y si se crea una analogía entre el cuerpo de texto y el cuerpo humano con los sesgos de placer y goce? Así resulta congruente pensar en dos rutas de análisis de la fenomenología del cuerpo: el que se vincula con la inmediatez del placer normativo en confrontación con el goce, que orilla a releer los estados del cuerpo desde la crisis de lo establecido; obliga a crear

$3 \quad$ Hans Robert Jauss defiene a la experiencia estética como el goce de lo bello, sea en temas trágicos o cómicos, aún cuando aquí, su definición de goce es más cercana a una experiencia satisfactoria, radicalmente distinta a la propuesta por Barthes, la cual se desarrollará más adelante. En este punto del presente ensayo, se retomará la especificación que hace Jauss en cuanto a la experiencia estética desde su Aisthesis: "designa la experiencia estética fundamental de que una obra de arte puede renovar la percepción de las cosas, embotada por la costumbre" (Jauss, 1972, p. 5). 
nuevas rutas de entendimiento y, en más de un sentido, esa es la ruta de creación de conocimiento nuevo.

La dicotomía entre placer y goce propuesta por Barthes es en sí un eco más de varios planteamientos hechos por autores como Nietzsche y sus conceptos apolíneo y dionisíaco; el primero representa la razón, el segundo el exceso y la orgía, y ambos forman las dos caras de una sola moneda. En El barroco y neobarroco, editado por El Cuenco de Plata, Valentín Díaz aborda la cercanía entre Severo Sarduy y Roland Barthes; califica a El placer del texto como un libro de ruptura: "Allí las referencias al barroco y a Sarduy son algunos de los fundamentos de la nueva ética de la literatura planteada en torno a las variables placer/goce" (Sarduy, 2011, p. 64).

Para Barthes, el intersticio existente entre placer y goce es un espacio que funciona en tensión, y es ahí donde se genera el erotismo. Para Sarduy, el neobarroco es el espacio de choque entre el abigarramiento del barroco y el vacío; este último, esencia de movimientos como el minimalismo y el arte conceptual. Así lo comenta Anna María Guasch:

Tras el referente manierista que Achille Bonito Oliva esgrimió para sentar la transvanguardia, a finales de los años ochenta, la mirada janica que tenía un ojo puesto en el presente y otro en el pasado fijó su atención en el barroco. Entre otros Io hicieron Severo Sarduy, Guilles Deleuze, Guy Scarpetta, Omar Calabrese, Francisco Jarautta, José Luis Brea, Massimo Cacciari y Christine Buci-Gluksmann, y lo hicieron al mismo tiempo que se renovaba el interés por las maneras minimalistas ${ }^{4}$. Ello favoreció procesos de contaminación entre dos conceptos estilísticos y entre dos territorios culturales antagónicos, lo minimal y lo barroco, caracterizado uno por su estética fría, geométrica, lógica y aséptica y, el otro, por el exceso, la inestabilidad, la metamorfosis, el caos, el laberinto, el fragmento, la complejidad, la dispersión y la perversión (2000, pp. 429-430).

Guasch cita a Sarduy, quien encuentra en lo barroco, no la referencia a un periodo histórico,

sino una cualidad formal de los objetos que lo expresan, es decir una categoría estética; propuso la denominación de neobarroco para calificar un periodo dominado por el discurso de la contradicción, el choque, el entrecruzamiento, la paradoja, y principalmente por la sobrevaloración de lo subjetivo ante el inocuo reduccionismo formal (2000, p. 430).

La serie de pinturas realizadas en conjunto entre Andy Warhol, Jean Michel Basquiat y Francesco Clemente, es un buen ejemplo de esta combinación ambivalente entre el signo carente de significado, uno de los pilares del conceptualismo, en unión con el grafiti y la transvanguardia, estos dos

4 Resulta paradójico -y evidentemente pendular- que Guasch mencione a estos autores como pensadores del discernimiento barroco posmoderno, como una respuesta del minimalismo, cuando fue el minimalismo que dio origen al cuestionamiento barroco. 
últimos contestatarios ante el primero. En esa misma línea, podríamos hablar que en estos cuadros se materializa la presencia simultánea entre lo apolíneo y lo dionisíaco, entre el vacío y el miedo al vacío -que es el barroco-, entre placer y goce, y es en este intersticio donde presenciamos el erotismo, un erotismo semiótico. Barthes "... traza dos límites; uno prudente, conformista, plagiario que ha sido fijado por la escuela, el buen uso, la literatura, la cultura, vs. el otro límite, móvil, vacío, allí donde se entrevé la muerte del lenguaje" (Barthes, 2011, p. 15). Concluye que el erotismo ocurre en el intersticio entre el primer límite y el segundo, en el espacio existente entre los dos bloques.

¿Será posible trasladar esta ruta de pensamiento y hablar de la erótica de la enfermedad? Del mismo modo que Witkin puede ser leído desde el entendimiento del pensamiento post estructuralista, ¿el sida puede ser tema de construcción de nuevos sentidos y nuevos entendimientos de la corporalidad serovinculada? ¿Existe erotismo en la enfermedad?

\section{Enfermedad y arte}

Las fotografías de Joel Peter Witkin emplean estrategias abyectas que incluyen cadáveres y corporalidades excéntricas; delinean la ruta del goce que resulta de confrontarnos con cuerpos para nada idealizados; es una invitación a transformar el entendimiento del cuerpo a partir de razonar desde las observaciones planteadas por Georges Bataille. ¿Y si permuto al cadáver como elemento poético por el cuerpo enfermo? Propongo el uso del goce de Barthes como estrategia para la construcción de la corporalidad de reciente aparición: la vinculada al VIH.

En la historia se encuentran innumerables ejemplos en los que se ve la tensión entre el placer y el goce de Barthes; como primer ejemplo, citaré la obra Napoleón visita la casa de los enfermos en Jaffa de Antoine-Jean Gros. En ella, se observa al Emperador francés en el acontecimiento ocurrido el 11 de marzo de 1799. El cuadro fue pintado en Versalles, en 1804, por encargo del Estado francés. Una obra excepcional por sus valores pictóricos formales y su clara visión de inicio del siglo XIX. Además, es evidente que se trata de una pieza de propaganda oficial, una especie de anticipación a lo que Lady Diana llevaría a cabo mediáticamente en el siglo XX. Napoleón es, en esta obra, la figura política, cabeza del poder del imperio. Toca la piel de un enfermo, en señal de cercanía con el dolor del soldado. Esto hace recordar las giras de Juan Pablo II, la Madre Teresa de Calcuta, Michael Jackson, Ricky Martin, We are the World, ¿Dónde jugarán los niños?, entre otras. Es decir, la figura mediática posa para salir en la fotografía del recuerdo. Es una imagen placentera en todos los sentidos. El manejo del dibujo y de la pintura en sí, no genera reto alguno al espectador de entonces ni al de ahora. Es inmediata y literal. 
Enrocando los contextos, se genera sentido al observar Baco enfermo de Caravaggio (1593). El anfitrión de la orgía se entrega a la fiesta aún enfermo. Nadie habló que el ritual terminara, sino que la mirada, el proceso de la fiesta se tornará con matices mórbidos como la piel que pinta Caravaggio, por cierto, cliente frecuente en la zona del conflicto interno y el exceso del festejo dionisíaco, pero ¿cómo es este exceso en la erótica de la enfermedad? En todo caso, ese homenaje que los romanos hacían a Baco es, en muchos sentidos, reivindicación, reafirmación de vida. Es el festejo de Bataille, erotismo sagrado que contiene pulsión de muerte. Las ausencias causadas por complicaciones relacionadas con el VIH nos involucran con lo sublime, aportan a la continuidad universal.

El duelo de la comunidad post sida muchas veces se transforma en relación destructiva, de atracción y rechazo simultáneo. La comunidad post sida somos todos aquellos que vivimos afectados por las consecuencias de la enfermedad, ya sea por ser seropositivos o seronegativos, cercanos a las consecuencias que el sida ha generado.

\section{La enfermedad como festejo; el arte como festejo ${ }^{5}$}

Propongo observar las intersecciones entre el goce de Barthes, el erotismo de Bataille y el arte de las minorías post globalización como marco teórico para leer el matiz corporal que la enfermedad genera. Barthes encuentra que el erotismo se produce en la tensión entre goce y placer, entre lo apolíneo y lo dionisíaco; por lo tanto, entonces, se puede pensar en una erótica de la enfermedad, de forma específica, en la erótica de la seropositividad o del sida. Esta erótica de la enfermedad se puede observar en varios momentos. Un primer ejemplo es la investigación de Alberto Teutle (Teutle \& List, 2015) en el que el fenómeno del sexo entre varones en la ciudad de Puebla es, a la vez, el producto de una investigación antropológica sobre el fenómeno de la sexualidad dionisíaca ejercida por un importante sector de la población del citado Estado mexicano; investigación que es viable en cientos de ciudades alrededor del mundo donde esto ocurre.

Las saunas de encuentro sexual entre varones fueron dibujadas en el grabado El baño de hombres, realizado por Alberto Durero en 1496 (Museo Nacional del Prado, 2005) y, si se busca "saunas gay" en el motor de búsqueda Google, aparecen 454000 resultados en 0.67 segundos. Wikipedia, por su parte, describe el fenómeno también. Es un evento de placer y goce, es tema de análisis y lugar de festejo. Este es el festejo de todos los tiempos,

$5 \quad$ Para más información leer Sangrador, R. (2016). Arte, placer y goce en el cuerpo post sida. En Mauricio List y Fabián Giménez (Coords.), Tratado breve de concupiscencias y prodigios ( $p .74)$. México: La Cifra Editorial. 
es el instante eterno de la fiesta en el Carnaval de Venecia que observa Mijail Baitin en La cultura popular en la edad media y en el renacimiento. El contexto de François Rabelais (1987, p. 9). Se trata del festejo en el que se disuelven, desaparecen o se crean reglas y estatus sociales.

Dionisios aglutina todos los excesos. Tal como se mencionó, el texto de Bajtin aborda el exceso y festejo del carnaval en Venecia, pero este tipo de experiencia la misma encontrada en los festejos azteca, romano, barroco Luis XV, hindú siglo $X$, neoyorquino siglo XXI, Ciudad de México siglo XIX, entre otros. Es el festejo del que habla Bataille, que incluye al sacrificio sagrado y es una manera de invocar la continuidad del tiempo y la continuidad de la vida.

¿Cómo es el festejo batailliano entre los clientes de los baños de vapor en la Ciudad de Puebla? La mayoría de los establecimientos con ese giro se encuentran en barrios populares, cerca de la Central de Autobuses de Puebla (CAPU). Al ingresar, se dejan en los lockers o casilleros las señas de la clase social, y cada quien se presenta ante los demás desnudo; el sudor es el sudor de todos mezclado en uno solo y, aunque en las regaderas existan ciertos límites, en los cuartos de vapor y baño turco, todos son partícipes de la orgía de todos los tiempos. Todos los ahí presentes son máquinas deseantes de unirse a un flujo (Deleuze, 2012), hasta llegar al éxtasis del orgasmo y a una eyaculación multitudinaria. Las planchas con los cuerpos desnudos son memento mori de las planchas en la morgue, los que no están en erección, están en la pequeña muerte, en período refractario (Unidad de Medicina Sexual) ${ }^{6}$. Esto es un primer fenómeno que representa de facto una ruta de estudio de sexualidad desde la intersección entre la antropología de la sexualidad y la línea del artista como etnógrafo desarrollada en el capítulo anterior.

\section{Duelo y militancia}

Douglas Crimp en Duelo y Militancia (2005, pp. 99-113) menciona que existe un conflicto entre pensamiento académico y activismo. El conflicto se crea al observar los orígenes y eventuales lugares finales de uno y otro. Es claro que se podrían realizar análisis semióticos con una infinidad de posibles cargas significativas, pero, esta vez dicho autor propone leer de modo simple, casi literal, sin añadir metáforas:

el duelo es un problema para nosotros; y por nosotros me refiero a los gays que se enfrentan al sida. Debería darse por hecho que no sólo los gays se enfrentan al sida, pero nosotros nos enfrentamos también a dificultades específicas, y con frecuencia únicas (2005, p. 100).

6 "De una manera clásica el período refractario solo se aplica al hombre, considerando que es el espacio de tiempo que necesita éste para volver a eyacular tras una eyaculación previa" (Unidad de Medicina Sexual, s. f.). 
Activismo y duelo tienen oposición interna dice Crimp. Añade que el punto es tratado anteriormente por Freud en Duelo y Melancolía de 1917:

La comprobación de la realidad, después de haber demostrado que el objeto amado ya no existe, necesita sin dilación que toda la libido se retire de su apego a dicho objeto. Contra esta necesidad surge por supuesto una lucha -se puede observar universalmente que el hombre nunca abandona de materia voluntaria una posición de libido, ni siquiera cuando un sustituto ya le está llamando-. Esta lucha puede ser tan intensa que surge un rechazo de la realidad, y se aferra al objeto por medio de una psicosis del deseo...

Todos los recuerdos y esperanzas que ataban la libido a su objeto salen a relucir y son hiper-catectizadas (cathexis: conexión entre ideas o entre una emoción y una idea), y se realiza la separación de la libido (Crimp, 2005, p. 102).

Crimp cita a Freud y el concepto psicosis del deseo propuesto para definir el cuadro que ocurre cuando existen vínculos eróticos y afectivos entre alguien que ha muerto de forma reciente y un sobreviviente de dicha relación. En las observaciones de Freud, la libido permanece un periodo en el deudo, hasta que es posible pensar en una división, no obstante, es un proceso largo y no abrupto. Esta psicosis del deseo ahora puede ser aplicada a gran parte de la comunidad que ha sobrevivido a la pandemia del sida; es decir, todos tenemos historias de ausencias, de amigos, familiares y amantes que han enfermado y muerto. El ego se vuelve libre y desinhibido de nuevo, dice Crimp; sin embargo, el autor recuerda que es importante no olvidar que Duelo y Melancolía aborda solo el duelo patológico, es decir, la melancolía ${ }^{8}$, mientras que Darian Leader cree fundamental hacer una clara diferenciación entre los conceptos de duelo, melancolía y depresión (Crimp, 2005, pp. 102-103).

Así, el texto de Crimp va recreando el panorama y esboza cómo está entendida la confrontación entre duelo y militancia. Nos recuerda que no se debe olvidar que finalmente, como grupo, como generación post sida, hemos creado una historia colectiva, en gran medida unida, por el tejido resultante de las historias de luto, "asociados con nuestros amigos perdidos y los ataques diarios a nuestras conciencias. En pocas ocasiones una sociedad ha atacado tan ferozmente a sus individuos en momentos de pérdida" (Crimp, 2005, p. 104). Este autor cita el ejemplo del New York Times que, en la sección editorial del verano de 1989, propone guardar la calma, pues el sida se sabía concentrado en grupos de riesgo muy específicos y, cuando estos se hayan infectado y muerto, las estadísticas de contagio disminuirían:

7 Freud escribe en 1917 "Mourning and Melancholia"; Douglas Crimp cita la edición de J. Rickman (Ed.), A General Selection from the Works of Sigmund Freud, Nueva York, Anchor Books, 1989, pp. 125-126.

8 Resulta interesante el "duelo patológico" como definición de melancolía. En todo caso, es importante recordar que autores como Darian Leader y Julia Kristeva definen la melancolía como una ruptura en el proceso de superación del duelo: "Tendemos a repetir cosas cuando permanecemos atrapados en ellas" dice Leader (2011, p. 34). Kristeva, por su parte, habla de "un pasado que no pasa" (1997, p. 55). 
La violencia con la que nos enfrentamos es implacable, la violencia del silencio y la omisión es casi tan imposible de superar como la violencia del odio desatado y el asesinato. $Y$ porque esta violencia también profana la memoria de nuestros muertos, nos alzamos airados para vengarlos. Para muchos de nosotros el duelo se ha convertido en militancia (Crimp, 2005, p. 104-105).

Antes del sida, la fiesta del cuerpo -la orgía- se hacía de otra manera, ya sea en los cuartos oscuros de los bares y lugares de reunión homosexual, los cines porno, las saunas y vapores, los parques, chupar penes, lluvias doradas, poppers, fist fucking: "Nuestros placeres nunca fueron tolerados, nosotros los tomamos sin pedir permiso, y ahora también debemos estar de duelo por ellos ..." (Crimp, 2005, pp. 104-105).

Es momento de reconstruir nuestro placer sexual.

\section{Dos estudios de caso: Robert Gober y Raúl García Sangrador}

A continuación se presentan dos visiones de la erótica de la enfermedad, intersticios entre placer y goce: Robert Gober y Raúl García Sangrador.

\section{Robert Gober}

Nace en Estados Unidos en 1954. En el 2014 se presentó en el MoMA de New York la exposición The Heart Is Not a Metaphor. Fue una retrospectiva de su trayectoria como creador visual desde finales de la década de los setenta hasta ese momento. En Gober se puede hablar de un postconceptualismo; es evidente su necesidad por regresar una y mil veces a su infancia y juventud, como diría Kristeva, "es un pasado que no pasa" (1997, p. 55). Así, queda asentado que la melancolía es parte esencial de la obra; Gober recuerda constantemente su casa en una comunidad suburbana de Connecticut, Estados Unidos.

Robert es un niño de modos delicados y es víctima de acoso escolar durante toda su infancia, no solo por parte de sus compañeros, sino también por parte de los docentes, pues uno de los maestros le llama Gober Girl. A los 23 años de edad se afinca en New York City. El 3 de julio de 1981 aparece en el New York Times una nota que marca a Robert: las partituras del himno nacional de Estados Unidos con motivo de las fiestas patrias de ese país. Las partituras ocupan el $80 \%$ de la página. Al lado, una sola columna da la nota sobre 41 casos de homosexuales enfermos de un cáncer raro. Ocho han muerto.

La nota del New York Times se vuelve histórica, pues deja ver el poco interés que se le da a la enfermedad, incluso cuando se habla de ciertos hechos inquietantes como el posible origen viral de la enfermedad, y que la ciudad de 
New York esté claramente vinculada, pues los homosexuales enfermos han pasado por New York City recientemente, incluidos dos daneses (Gober, 2014, p. 57).

Robert Gober es homosexual y desde este punto participa en la producción de obra artística que parte de la identidad homosexual, la cual aporta a la pelea por sus derechos civiles y por los derechos a la salud. Por ejemplo, la serie de lavamanos que usa como elementos recurrentes ${ }^{9}$ hablan de su retorno simbólico a la niñez; es posible hablar en términos de melancolía, sobre todo cuando en su periodo adulto esos lavamanos son metáforas de cuerpos, cada uno es una persona. Ve en los orificios posibles pezones y, en el desagüe, ombligos, vaginas y penes.

La metáfora es llevada a nuevas situaciones cuando Gober confronta por completo el tema del sida y las muertes masivas que se estaban produciendo. Los lavabos, con carga simbólica humana, son ahora dos lápidas. En la museografía del MoMA, las lápidas están en una terraza, son vistas desde adentro de la sala de exhibición, donde se presenta una pieza Untitled, de 1986: una cama que, al igual que los lavabos, es presentada como una escultura en sí misma. Esa cama aislada y arrinconada representa la soledad en la que mueren los enfermos de sida.

Gober observa ominosamente su cotidianidad; todo es parte de una amenaza latente. A final de la década de 1980, inicia con la serie de piernas de cera con incrustaciones de vello propio. En continuidad con los lavabos, los desagües son heridas que bien pueden ser las marcas del sarcoma de Kaposi citado en la nota del New York Times del 3 de julio de 1981. Algunas piezas tienen en las nalgas las partituras del himno nacional estadounidense. Las notas parecieran negar la existencia del problema del sida, pero ¿qué pasa si quitamos las notas y en su lugar colocamos la noticia sobre el cáncer raro en 41 homosexuales? ¿Y si suplantamos los sarcomas por los desagües? La pieza se vuelve contundente porque, en realidad, lo que contienen es el desprecio con el que inicialmente se abordó a la enfermedad. Además, en la nota se decía que el cáncer raro de los 41 homosexuales iniciaba, por lo general, en las piernas. Gober no idealiza el cuerpo, al contrario, les coloca zapatos y calcetines, o trusas de algodón, para que las piernas de cera cobren el tono cotidiano, hogareño, lo cual es una constante este artista. Al colocarlas en el suelo, en medio de la sala, parecen una metáfora del poco interés que, en general, se le dio al tema por parte de la administración Reagan; las notas del himno tienen tono de reclamo. Las piernas son, en esta serie, piernas pasivas, receptoras. No muestran el pene; esperan ser penetradas por todos los que colaboran con el problema del sida, penetradas por la indiferencia y el aislamiento. En paralelo, Gober tiene una serie de piernas activas, donde el elemento fálico es una vela que, incluso, presenta como arte objeto y tienen vello púbico. 


\section{Raúl García Sangrador: El futuro es nuestro}

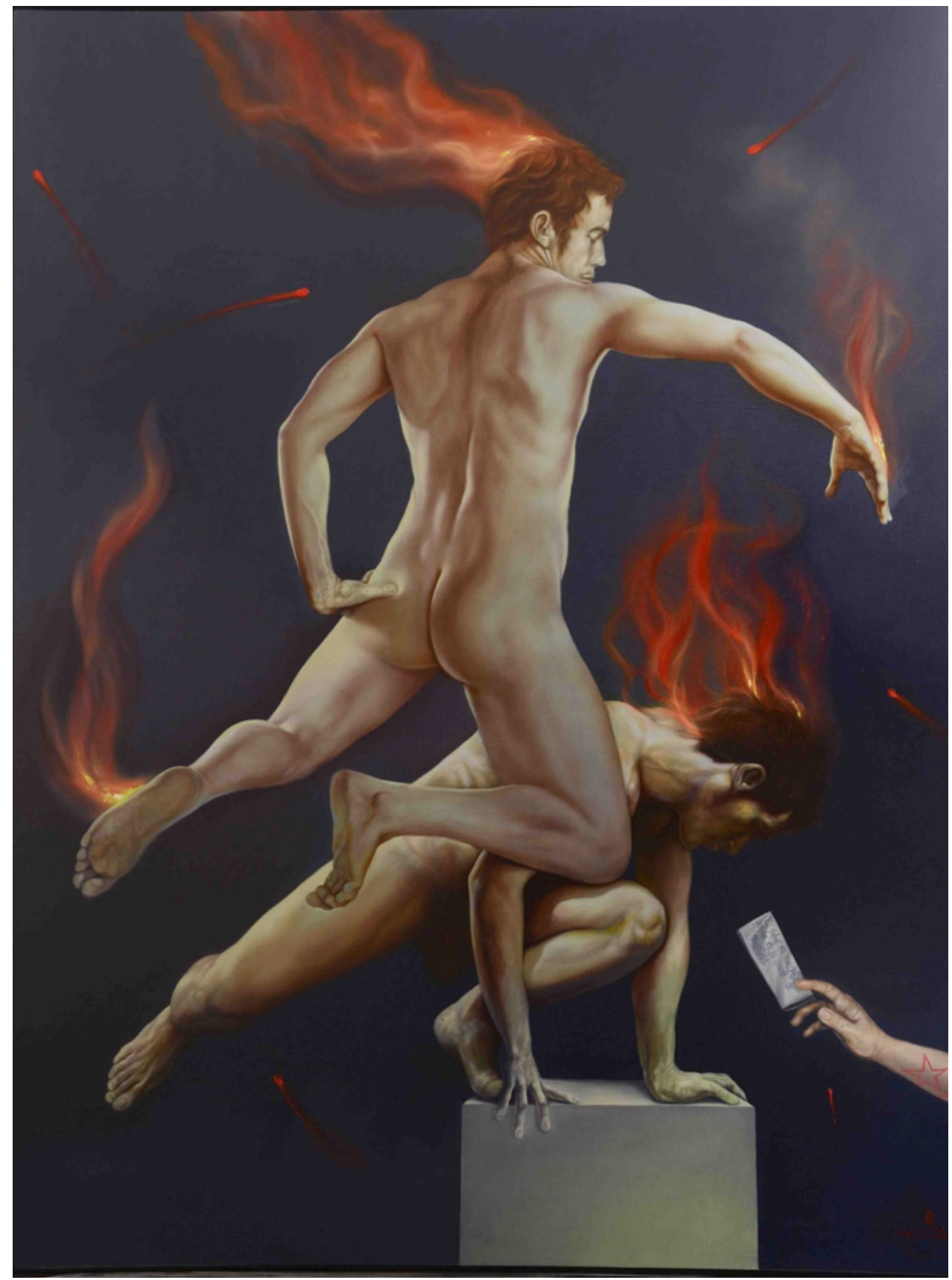

Raúl García Sangrador, El futuro es nuestro, óleo sobre lino, 130 × 170 cm, 2015. Colección Grupo MILENIO. 
Recuerdo que estaba en Times Square a la media noche, cuando recibí un correo electrónico de mi amigo Javier Uribe del periódico El Universal. Ambos decían que Avelina Lésper, del grupo MILENIO, me buscaba y que me pusiera en contacto con ella. Así lo hice y el resultado fue una entrevista, además del encargo de una pintura representativa de mi trabajo.

Así pinté El futuro es nuestro ${ }^{10}$, obra que busca narrar la historia de mi relación con el sida y las muertes que ha implicado. Todo inició en 1992, año en que llegué a la Ciudad de México a estudiar la Licenciatura en Diseño Gráfico en la Universidad Autónoma Metropolitana, Unidad Xochimilco. No conocía a nadie, pero de a poco fui creando amistad con las personas con las que me sentía especialmente vinculado, con quienes compartía gustos y visión de vida: la comunidad homosexual de la Ciudad de México. Formamos un grupo que en sí funcionó como un núcleo familiar; nos apoyábamos, compartíamos gastos, nos cuidábamos unos a otros. El más grande de todos era Alfonso, quien trabajaba como ejecutivo de cuenta en un banco. Un día, simplemente observé que su cuerpo estaba cambiando: el color de su piel se oscureció a un tono color ceniza, su cabello se aclaró y de ser ondulado se volvió lacio; empezó a bajar de peso dramáticamente. En el banco lo liquidaron -porque ya no podía trabajar- y le dieron una indemnización, con la que creamos una revista en la que vendíamos los espacios para publicidad y repartíamos de forma gratuita en los bares y lugares gay de la Ciudad de México.

Pero un día todo cambió; Alfonso se regresó a casa de sus padres en Puebla y nos dejó solos; únicamente regresó para despedirse cuando ya pesaba 30 kilos y no podía caminar. Poco después murió. Fue el primero, porque le siguieron Arturo, Edgar, Ismael, Jorge, Germán, Daniel, Sergio Alfonso, Paul y Bruno. Siempre pensé que el siguiente sería yo. Me convertí en el equivalente a Renton, el personaje de Trainspotting interpretado por Ewan McGregor: si de lo que se trata es de morir pronto, pues era momento de vivir al límite y poner fin a la existencia. En esos años me transformé en Dante, que pasea por el infierno con Virgilio y regresa a contar historias.

Así que la obra El futuro es nuestro se convirtió en el detonante de un proceso creativo, vinculado por mi historia personal con el tema del sida en México. Poco después de entregar la pieza a Avelina Lésper, hice contacto con el Colegio de Antropología Social de la Benemérita Universidad Autónoma de Puebla, donde se encuentra un grupo de investigadores que, desde hace varios años, aborda el tema de la corporalidad vinculada a la enfermedad, en este caso, el sida. De pronto estaba en medio de un diálogo con la enfermedad desde la Antropología y el Arte. Para este punto retomaré un fragmento del libro Húmedos Placeres (Teutle \& List, 2015) descrito en La enfermedad como festejo, el arte como festejo:

10 Para más información, véase https://www.youtube.com/watch?v=sKLmu2XKqoM\&t=105s 
El estudio que a continuación presento se centra en el espacio masculino del vapor en Puebla y específicamente en los baños generales de hombres de los barrios populares. Considero que son espacios en los que la homosocialidad y la desnudez entre sus usuarios han llevado a trastocar las relaciones convencionales entre varones. Estos baños han dado cabida a las relaciones sexuales debido a la permisividad que hay del uso del espacio. Aunque no se pueda firmar que el mismo fenómeno esté presente en todos los baños públicos de vapor de Puebla; tampoco se puede soslayar que son espacios en los que eventualmente se da la posibilidad de la práctica sexual (Teutle \& List, 2015, p. 17).

El libro de Teutle y List me pareció revelador pues, a partir de la premisa descrita por Hal Foster en “El artista como etnógrafo” (Foster, 2001), se abrió ante mí la posibilidad de desarrollar un proceso creativo fundamentado en la observación etnográfica de las prácticas de riesgo que la comunidad homosexual post sida ejerce a manera de festejo. De forma específica, El futuro es nuestro es en sí un testimonio de mi generación, profundamente afectada por la psicosis del deseo. Además del duelo, el cuadro representa el instante eterno que menciona Bajtin (1987, p. 9). En ello radica que sea una pieza de la erótica de la enfermedad en la que se intersectan placer y goce a través de la representación de corporalidades mórbidas transfiguradas por el proceso de muerte. Las figuras que ahí aparecen son, en sí, dos ausencias producidas por el sida, pero, en paralelo, son dos cuerpos más, dentro de los lugares de encuentro sexual como en los baños de vapor de Puebla, igual que en la orgía dionisíaca, en el bacanal, en donde el sudor de todos se vuelve el mismo sudor y donde los cuerpos son todos los cuerpos, y la pequeña muerte se transforma en éxtasis, en continuidad.

De nuevo estoy frente al festejo de Bataille, que invoca a la muerte mediante el riesgo de infectarse de VIH. El neobarroco descrito por Sarduy, llevado al goce de Barthes, señala una ruta de pensamiento ante la representación de la corporalidad vinculada al sida y al ejercicio de la sexualidad entre hombres. En alguna ocasión pensé en presentar como signos banales las fotografías de mis amigos enfermos de sida, como en el arte conceptual, y que esa falta de sentido devolviera un poco de paz a sus cuerpos dolientes.

A la generación post sida, a los que vimos avanzar el fenómeno de la enfermedad y que seguimos vivos, nos cuesta trabajo planear el futuro. Personalmente pensé que, al igual que todos mis amigos y demás gente muerta a causa del sida, yo también moriría joven, pero no ha sido así... por primera vez empecé a hacer planes para después. Tal vez llegue a ser un hombre viejo y debo de estar preparado. Esa es la razón del título del cuadro: ese futuro lo viviremos todos juntos, ellos conmigo; soy el resultado de haberlos conocido, de sus historias junto con las mías. 


\section{Conclusiones}

"La consumación de la libido está en la muerte" (Nostalgia del Absoluto, Steiner, 2004, p. 34).

A partir del concepto del goce de Barthes se puede hablar de erótica de la enfermedad como el espacio de tensión, en este caso, entre conceptos que llegaron con el sida. De inmediato se diversifica en múltiples líneas de investigación; intersticios entre salud, enfermedad, sexualidad, género, alteridad, corporalidad y demás posibilidades. El éxtasis del que habla Bataille es obtenido por otras rutas que van desde las maneras de procurarse un orgasmo, hasta las nuevas maneras de morir. El sida es un fenómeno político; el arte que aborda el tema del VIH es evidentemente arte político.

El enfermo de sida es un nuevo personaje en la puesta en escena del presente y trae consigo una lista de nuevas instancias que abordar. La construcción actual de género tiene que ver con el goce de Barthes, es decir, la sexualidad llevada al entendimiento, a su raciocinio, lo que de entrada plantea tantas diversidades como maneras de comprender el ejercicio de la sexualidad. Aquí, la generación post sida solicita participar en el recuento histórico. El presente ensayo, además busca los vínculos con el arte actual que sintoniza desde la psicosis del deseo. Los vivos interconectamos, sincronizamos con los que ya no están; somos su consecuencia.

La fiesta, la orgía post sida, se está reconstruyendo; la pulsión de muerte continúa en las maneras de ejercer la sexualidad dentro de un sector importante de hombres, por ejemplo, los clientes frecuentes de los vapores en la Ciudad de Puebla que, como en cientos de otras ciudades, se reúnen a tener sexo anónimo y así involucrarse con la continuidad de Bataille, participar en el festejo eterno, en la fiesta de todos los tiempos. El VIH está en todo el planeta, su presencia es ominosa y nos observa a todos constantemente; la práctica del sexo seguro o del sexo protegido es cuestión de vida o muerte, aísla a los individuos, pero no hacerlo involucra flujos corporales que, eventualmente, pueden estar infectados; se crea una sociedad de la ansiedad, una sociedad del miedo, donde el sida es solo una pequeña parte de lo que puede salir mal. Esa ansiedad, en todo caso, se ha vuelto ingrediente de la fiesta post sida, se ha convertido en coqueteo con la muerte.

El goce de Barthes invita a confrontar analíticamente, desde el entendimiento, esta combinación de prácticas de riesgo, arte, sexualidad, VIH y corporalidades adyacentes. Su análisis, en unión con el fenómeno de las prácticas sexuales vinculadas al sida, resultan en una posible lectura de la erótica de la enfermedad.

Las prácticas sexuales de la comunidad post sida, como ya hemos dicho, se transforman en políticas públicas, como el intento por clausurar el último vagón del metro en la Ciudad de México o censurar zonas de ligue 
sexual; en todo caso, es claro que estos agenciamientos del orgasmo nunca desaparecerán. En México, las reflexiones neomexicanistas dieron lugar a la aceptación de las prácticas homosexuales como semillas de nuevas poéticas dentro del arte establecido, antes disimuladas y ahora visibilizadas. Después de la aparición del VIH todo cambió; en un futuro inmediato se desearía la cura definitiva, que regrese de lo fatal a lo banal. Aun así, quedaríamos resignificados de nuestros rituales eróticos y sexuales. Implica la lucha por nuevas libertades. Ahora, el encuentro casual y anónimo es apoyado por una aplicación que me conecta con quien tener sexo. Solo necesito un teléfono inteligente y una conexión a Internet.

Es importante acrecentar la producción artística vinculada al sida en México; es posible que la red de instituciones de Educación Superior del país produzca obras y publicaciones bajo método, como ya es una realidad desde hace veinte años en el Taller de Documentación Visual de la Universidad Nacional Autónoma de México, lamentablemente desaparecido en 2016, tras la muerte de su creador, Antonio Salazar.

No olvidar que la presente investigación surgió a partir de haber vivido los sucesos de la historia del sida. Los nacidos en la década de los setenta que aún vivimos, hemos sobrevivido a la espera de ciertas respuestas sobre la enfermedad; ahora tenemos la responsabilidad de documentar, dar testimonio y difundir todo lo ocurrido, anteponiendo el raciocinio de la enfermedad como tema creador de experiencia estética.

Este texto está dedicado a todos mis amigos de la UAM Xochimilco que han muerto por complicaciones propias del sida, hasta siempre.

\section{Referencias}

Altman, Lawrence. (July 3, 1981). Rare Cancer Seen in 41 Homosexuals. New York Times, A20. Recuperado de http://www.nytimes.com/1981/07/03/ us/rare-cancer-seen-in-41-homosexuals.html?mcubz=1

Bajtin, Mijail. (1987). La cultura popular en la Edad Media y el Renacimiento. El contexto de François Rabelais. Argentina: Facultad de Filosofía y Letras de la Universidad de Buenos Aires.

Barthes, Roland. (2011). El placer del texto y lección inaugural. (2da ed.). México D. F., México: Siglo XXI Editores.

Bataille, Georges. (1970). Breve historia del erotismo. (Traductor Drazul Alberto). Montevideo, Uruguay: Ediciones Calden.

Bataille, Georges. (2002). Las lágrimas de Eros. Barcelona, España: Tusquets Editores.

Byung-Chul, Han. (2014). La agonía del eros. Barcelona, España: Herder Editorial. 
Círculo Cultural Gay. (2002). Una exposición, varias exposiciones, un tiempo de inauguraciones. Difusión Cultural Universidad Nacional Autónoma de México, Museo Universitario del Chopo, Círculo Cultural Gay. México D. F.: José María Covarrubias.

Crimp, Douglas. (2005). Posiciones críticas, ensayos sobre políticas de arte y la identidad. Madrid, España: Akal.

Deleuze, Gilles. (2012). Mil mesetas. Capitalismo y esquizofrenia. Valencia, España: Pre-Textos.

DOL Films Productions. (2003). The Gift [YouTube]. Recuperado de https:// www.youtube.com/watch?v=oN4w8e432

Foster, Hal. (2001). El retorno de lo real. Madrid, España: Akal.

Freud, Sigmund. (1979). Duelo y melancolía. Obras Completas. (Vol. XIV). Buenos Aires, Argentina: Amorrortu Editores.

García Düttmann, Alexander. (2000). Between Cultures/ Tensions in the Struggle for Recognition. London/New York: Verso.

García Sánchez, Raúl. (2013). Búsqueda del origen de la melancolía en la pintura de Enrique Guzmán y Julio Galán. Universidad Autónoma de Querétaro-Facultad de Bellas Artes. Maestría en Arte y Sociedad. Querétaro: Universidad Autónoma de Querétaro.

García Sangrador Raúl. (2015). El futuro es nuestro. Óleo sobre lino, 130 ×170 cm, México: Colección Grupo MILENIO.

Gober Robert, A. H. (2014). The Heart Is Not a Metaphor. New York City, USA: The Museum of Modern Art.

Guasch, Anna María. (2009). El arte último del siglo XX. Del posminimalismo a lo multicultural. España: Alianza Forma.

Jauss, Hans Robert. (1972). Pequeña apología de la experiencia estética. Barcelona, España: Paidós.

Kristeva, Julia. (1997). Sol negro. Depresión y melancolía. Caracas, Venezuela: Monte Ávila Editores Latinoamericana.

Leader, Darian. (2011). La moda negra. Duelo, melancolía y depresión. Madrid, España: Sexto piso.

Milenio. (2015). ¿Por qué tengo que guardar silencio [YouTube]. Recuperado de https://www.youtube.com/watch?v=sKLmu2XKqoM\&t=105s

Monreal Tejada, Luis. (1983). Obras Maestras de la Pintura. Louvre/Jeu de Paume (Vol. I). Madrid, España: Editorial Planeta. 
Museo Nacional del Prado. (2005). Durero, obras maestras de la Albertina. (M. d. Museo Nacional del Prado, Ed.) Madrid, España: Museo Nacional del Prado, Comunidad de Madrid, Ministerio de Cultura de España.

Newman, Robert. (January 11, 2014). Why We Fight: AIDS and ACT UP. Recuperado de http://www.robertnewman.com/why-we-fight-aids-and-act-upposters-of-the-1980s-and-90s/

Sarduy, Severo. (2011). El barroco y el neobarroco. Buenos Aires, Argentina: El Cuenco de Plata.

Sontag, Susan. (2003). La enfermedad y sus metáforas. El sida y sus metáforas. Madrid, España: Punto de Lectura.

Steiner, George. (1974). Nostalgia del Absoluto. Madrid, España: Editorial Siruela.

Teutle, Alberto \& List, Mauricio. (2015). Húmedos placeres/ Sexo entre varones en saunas de la Ciudad de Puebla. México D. F., México: La Cifra Editorial

Unidad de Medicina Sexual [UMS]. (2015). Período refractario. Recuperado de https://www.unidadmedicinasexual.com/blog/educacion-sexual-medicina-sexual-suelo-pelvico/periodo-refractario

Welsh, Irvine. (2013). Trainspotting. México D. F., México: Anagrama.

Wikipedia. La Enciclopedia Libre. (2017). Sauna Gay. Recuperado de https:// es.wikipedia.org/wiki/Sauna_gay 